\title{
CORRECTION
}

\section{Correction to: Accuracy of genomic selection to predict maize single-crosses obtained through different mating designs}

\author{
Roberto Fritsche-Neto ${ }^{1}(1) \cdot$ Deniz Akdemir $^{2}$ (I) $\cdot$ Jean-Luc Jannink ${ }^{3}$ (I)
}

Published online: 23 May 2018

๑) Springer-Verlag GmbH Germany, part of Springer Nature 2018

\section{Correction to: \\ Theoretical and Applied Genetics (2018) 131:1153-1162 \\ https://doi.org/10.1007/s00122-018-3068-8}

Unfortunately, the first author name of the above-mentioned article was incorrectly published in the original publication. The complete correct name should read as follows:

Roberto Fritsche-Neto

The original article can be found online at https://doi.org/10.1007/ s00122-018-3068-8.

Roberto Fritsche-Neto

roberto.neto@usp.br

1 Department of Genetics, "Luiz de Queiroz" Agriculture

College, University of São Paulo, Piracicaba, São Paulo,

Brazil

2 Cornell University, Ithaca, New York, United States

3 Department of Plant Breeding and Genetics, Cornell University, Ithaca, NY, USA 